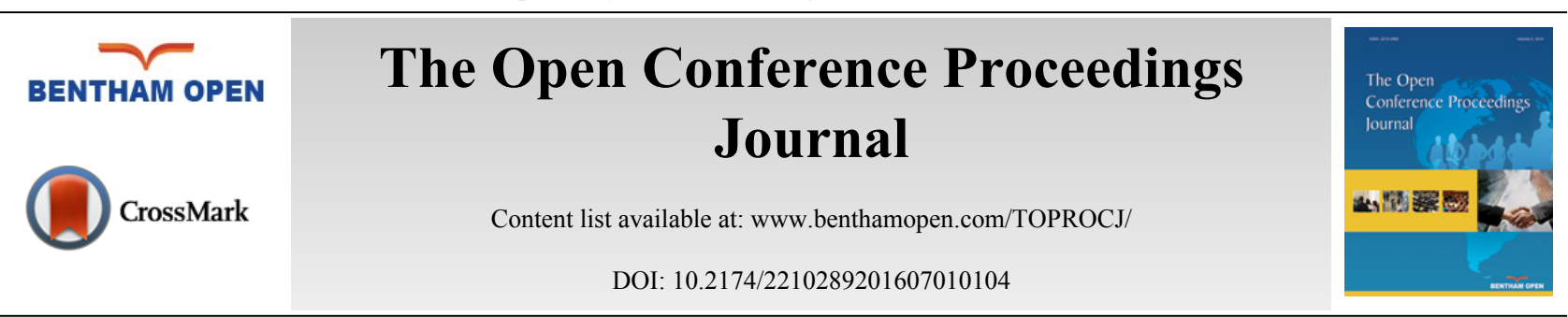

\title{
Antibacterial Activity and Preliminary Phytochemical Screening of Endophytic Fugal Extract of Rauvolfia serpentina
}

\author{
Santosh K. Singh ${ }^{1, *}$, Madhu Verma ${ }^{1}$, Amit Ranjan ${ }^{2}$ and Rajesh K. Singh ${ }^{3}$ \\ ${ }^{l}$ Centre of Experimental Medicine and Surgery, Institute of Medical Sciences, Banaras Hindu University, \\ Varanasi-221005, India \\ ${ }^{2}$ Department of Kayachikitsa, Institute of Medical Sciences, Banaras Hindu University, Varanasi-221005, India \\ ${ }^{3}$ Department of Dravyaguna, Institute of Medical Sciences, Banaras Hindu University, Varanasi-221005, India
}

Received: October 11, 2015

Revised: March 02, 2016

Accepted: April 04, 2016

\begin{abstract}
Endophytic fungi isolated from Rauvolfia serpentina, a well known Indian medicinal plant, is used in Ayurveda for treatment of many diseases. Isolated endophytes were screened for their antibacterial activity against pathogenic bacteria. Twenty fungal isolates were recovered from different parts of the host plant and they were characterized for their morphological features through Scanning Electron Microscopy (SEM) and on the basis of observations they were grouped in eight genus as Fusarium sp., Phomopsis sp., Colletotrichum sp., Cladosporium sp., Aspergillus sp., Xylaria sp., Alterneria sp. and Gleomastix sp. The secret of the fungal endophytes of this medicinal plant was revealed by the evaluation of the extract against the target bacteria. The extracts of four fungal isolates Colletotrichum sp. (Rs-R5), Fusarium sp.(Rs-R1), (Rs-R7) and Cladosporium sp.(Rs-S4) among twenty isolates were found effective against human pathogenic bacterial strains E. coli (ATCC 25922), Gram negative bacteria and S. aureus (ATCC 25323), Gram positive bacteria. Ethyl acetate extract of active fungal isolate (Colletotrichum sp; Rs-R 5) was most effective than other extract, with maximum inhibition zone $16 \mathrm{~mm}$ and $14 \mathrm{~mm}$ and minimum MIC $25 \mu \mathrm{g} / \mathrm{ml}$ and $36.5 \mu \mathrm{g} / \mathrm{ml}$ against $E$. coli and $S$. aureus respectively.
\end{abstract}

Keywords: Antibacterial activity, fungal endophytes, phytochemical screening and bioactive strains.

\section{INTRODUCTION}

Rauvolfia serpentina (family Apocynaceae) is a well known medicinal plant used as anti-hypertensive remedy [1, 2]. In Ayurvedic literature, the powdered root of this plant has been used for the treatment of snake bites, feverish illnesses and mental illness from ancient time [1]. It is also known for its antimicrobial, anti-inflammatory, antioxidant, antiproliferative, anticancerous, antidiuretic, antifibrillar, antiarrhythmic, anticholinergic, antidysentry, antidiarrhoeal, antihypotensive, anticontractile, sympathomimetic and tranquillizing activity in many research work of modern time [3 - 8]. It is also an important medicinal plant in the pharmaceutical world due to the presence of its immense therapeutic properties for curing various disorders because of the presence of alkaloids, flavonoids, glycosides, phlobatannins, phenols, resins, saponins, sterols, tannins and terpenes [9]. The major alkaloids present are ajmaline, ajmalicine, ajmalimine, deserpidine, indobine, indobinine, reserpine, reserpiline, rescinnamine, rescinnamidine, serpentine, serpentinine and yohimbine [10].

Alkaloids in their pure form and also their synthetic derivatives are useful for their medicinal application as an analgesic, antispasmodic and bactericidal effects [11,12]. Reserpine is most prominent alkaloid with sedative and antihypertensive activities which are used as tranquilizer and in control of high blood pressure and also most prominent ajmaline with antiarrhythmic activity [13]. Such valuable medicinal plants are likely to be threatened due to their over

\footnotetext{
* Address correspondence to this author at the Centre of Experimental Medicine and Surgery, Institute of Medical Sciences, Banaras Hindu University, Varanasi-221005, India; Tel: +91-9415389046; Email: singhsk71@yahoo.com
} 
exploitation for therapeutic uses, so the study of endophytes of this plant may provide a good alternative source for the unique secondary metabolites.

Endophytes are reported to produce bioactive molecules which were originally reported from their host medicinal plant. This concept was established after the isolation of potent anticancer molecule taxol from Taxomyces andreanae an endophyte isolated from host plant Taxus brevifolia. This is for the first time an endophytic fungus was recognized as an alternate source of taxol, initially Taxus brevifolia was the only source of taxol [14]. Similarly some other chemicals like camptothecin, podophyllotoxin, hypericin and piperine were isolated from endophytes other than the host plant [15 - 18].

Endophytes are ubiquitous, endosymbiont, often a bacterium or fungus which survive in the various living tissues (especially leaves, stems, roots) of plants without any harmful effects to the host plants [19]. These microorganisms colonize in the intercellular and intracellular region of the host plant and the population of certain endophytic species ranges from several to a few hundred strains [20,21]. Endophytes have been reported for their significant application in medicine, agriculture and biofuels. Selected endophytes play an important role in the host defense mechanism also [22].

Bioactive metabolites isolated from endophytes have a broad spectrum of biological activities such as antimicrobial, antiviral and anticancer $[23,24]$. The great expectation of patients over modern medicine and more awareness about side effects of synthetic drugs had made the pharmaceutical industries to turn towards herbal drugs but it causes huge exploitation of valuable medicinal plants and massive depletion of biodiversity. These possibilities exist for those who desire to venture into the wild and unexplored territories of the world to experience the excitement and thrill of being engaged in the discovery of endophytes, their biology, and their potential usefulness [21]. In this study the plant was screened for its endophytic fungi and also fungal extracts were evaluated for antibacterial activities.

\section{MATERIAL AND METHODS}

Four healthy medicinal plants of $R$. serpentina were collected randomly from different sites near Varanasi $\left(25.5^{\circ} \mathrm{N}\right.$, $82.9^{\circ} \mathrm{E}$; elevation, $279 \mathrm{ft}$ per $85 \mathrm{~m}$ ) during rainy season (July-August). Healthy tissues (leaves, roots and stem) were collected and the ends were trimmed then sealed with parafilm ${ }^{\mathrm{TM}}$ and kept in the sterile polythene bags. All the samples were brought to the laboratory in an icebox and used to screen for endophytic fungi within $48 \mathrm{~h}$ of collection.

\section{Surface Sterilization of Plant Samples}

The roots, stems and leaves were cut into small pieces $(1.0 \times 1.0 \mathrm{~cm})$ with sterile pinch cutter and these samples were initially surface treated to eliminate the epiphytic microorganisms. The samples were immersed in $70 \%$ ethanol for $1-3$ min and then in aqueous sodium hypochlorite (4\% available chlorine) for 3-5 min and then rinsed in $70 \%$ ethanol for nearly $30 \mathrm{~s}$, before a final rinse in sterilized double distilled water and after that each sample was dried under aseptic conditions. Streptomycin $(100 \mu \mathrm{g} / \mathrm{ml})$ was used in potato dextrose agar media to control the bacterial contamination according to the method described by Hallman et al. [25]. Four segments of tissue sample were placed on each Petri plate of culture media. The parafilm ${ }^{\mathrm{TM}}$ sealed Petri dishes were then incubated in a Biochemical oxygen demand incubator for 25 days at $12 \mathrm{~h} \mathrm{light/dark} \mathrm{cycle} \mathrm{at} 27 \pm 2^{\circ} \mathrm{C}$. The plates were examined on alternate days, and hyphal tips of actively growing fungi were then subcultured.

\section{Identification of the Endophytic Fungal Strains}

The structure of conidia and hypae was studied by colony morphology and under Light microscope, (Manual of soil fungi Gilman et al. 1945; Bernett et al. 1998; Ellis 1971 \& 1978; Vanarx 1978; Raper \& Thom 1949) [26 - 29] and also by Scanning Electron Microscopy (at CSIR-IITR, Lucknow). The SEM (standard lab manual) squares or discs with about $0.5 \mathrm{~cm}$ of mycelia of a fungus were immersed in a microcentrifuge tube with fixative solution $2.5 \%$ glutaraldehyde and kept for $24 \mathrm{hr}$ in a refrigerator. Then the specimens were washed in cacodylate buffer (three times, for 10 mins each wash). Now, post fix in $1 \%$ osmium tetraoxide aqueous solution in water for overnight at room temperature. Rinse three times in distilled water, followed by dehydration in crescent series of acetone solutions $(25 \%$, $50 \%, 75 \%, 90 \%$, and $100 \%$, once for concentration up to $90 \%$ and twice for the $100 \%$ concentration) for $10 \mathrm{mins}$ each. The samples were transferred to a critical point dryer to complete the drying process with carbon dioxide as a transition fluid. The specimen obtained was mounted on aluminum stub, with a double sided-stick carbon tape pasted on a film of aluminium foil, coated with gold in a sputter. Samples were then observed in SEM. 


\section{Fermentation and Extraction}

The grown cultures of endophytic fungus were inoculated into Potato Dextrose Broth and kept for 15 days at $27^{\circ} \mathrm{C}$ at150 rpm in BOD shaker incubator. After 15 days, the crude fermentated broth was filtered and fungal metabolites were extracted by solvent extraction method. Equal volume of methanol and filtrate was taken in the separating funnel and shaken vigorously for $10 \mathrm{~min}$ [30]. The separated fungal mycelia were thoroughly homogenized with methanol and were maintained for 48 hours in methanol. After this the methanol was centrifuged and the supernatant was collected and $98 \%$ concentrated under vacuum evaporator [31]. The extract was then dissolved in 1\% DMSO.

\section{Antibacterial Assay}

Endophytic fungal extracts were screened for their antibacterial activity by disc diffusion plate method. All the test strains of bacteria were sub-cultured and maintained in nutrient agar media. Streptomycin $(0.1 \mu \mathrm{g} / \mathrm{ml})$ was used to compare the antibacterial activity in fungal extract through disc diffusion method as described by Devi et al. [32]

\section{Minimum Inhibitory Concentrations of Fungal Extract}

The stock solution of extract of $1 \mathrm{mg} / \mathrm{ml}$ concentration was prepared and by serial dilutions (10 folds) various concentrations $(10-100 \mu \mathrm{g} / \mathrm{ml})$ were maintained to determine the minimum inhibitory concentration (MIC) values. The MIC value of endophytic fungal extracts was determined for Gram negative bacteria E. coli (ATCC 25922) and Gram positive bacteria $S$. aureus (ATCC 25323). The MIC values of fungal extracts were comparable to the MIC values of standard drugs as determined by a disc diffusion method according to the CLSI guidelines [33]. The concentration of both $E$. coli and S. aureus was $10^{6} \mathrm{CFU}$ using a MacFarland standard and spread on Mueller-Hinton agar media. The disc of $6 \mathrm{~mm}$ was loaded with the extract and transferred on Mueller-Hinton agar medium at $37^{\circ} \mathrm{C}$. MIC of the extract was determined after $48 \mathrm{~h}$ of incubation. The MIC value was considered as the lowest extract concentration with no visible growth.

\section{Preliminary Qualitative Phytochemical Screening}

\section{Alkaloids}

The fungal crude extract was evaporated to dryness in a boiling water bath. The residue was dissolved in $2 \mathrm{~N}$ HCl. The mixture was filtered and the filtrate was divided into 3 equal portions. Each portion was treated with a few drops of Mayers reagent, equal amount of Dragondroffs reagent and Wagners reagent respectively. The orange-brown precipitate indicated the existence of alkaloids [34].

\section{Flavonoids}

One $\mathrm{ml}$ aliquot of extract was mixed with $4 \mathrm{ml}$ deionized water and $0.3 \mathrm{ml}$ of $5 \% \mathrm{NaNO}_{2}$ was added. The mixture was allowed to react for 5 minutes. Following this, $0.2 \mathrm{ml}$ of $10 \% \mathrm{AlCl}_{3}$ was added and the mixture stood for further 5 min. Finally to the reaction mixture $2 \mathrm{ml}$ of $1 \mathrm{M} \mathrm{Na}_{2} \mathrm{CO}_{3}$ and $2.5 \mathrm{ml}$ deionized water were added. Yellow precipitate indicates the presence of flavonoids [35].

\section{Polyphenols}

Polyphenols presence was determined by spectrophotometric Folin-Ciocalteau method. $0.2 \mathrm{ml}$ of extract, $1.8 \mathrm{ml}$ of deionized water was mixed and then $10 \mathrm{ml}$ of Folin-Ciocalteau reagent and $8 \mathrm{ml}$ of $7.5 \%$ sodium carbonate were added. The mixture was heated in water bath at $45 \mathrm{C}$ for 15 minutes. Intense blue color indicates the presence of polyphenols [36].

\section{Tannins}

The fungal crude extract was treated with alcoholic $\mathrm{FeCl}_{3}$ reagent. A bluish black colour, which disappears on addition of a little dilute $\mathrm{H}_{2} \mathrm{SO}_{4}$ was followed by the formation of yellowish brown precipitate [37].

\section{Steroids}

The crude extract was taken in a test tube and dissolved with chloroform, and then an equal volume of concentrate sulphuric acid to the test tube. The upper layer in the test tube turned to red and lower layer showed yellow color with green fluorescence. It indicates the presence of steroids [37]. 


\section{Saponins}

The presence of saponins was verified by frothing test. The crude extract was vigorously shaken with distilled water and allowed to stand for $10 \mathrm{~min}$. Froth indicate the presence of saponins and no froth indicate the absence of saponins [38].

\section{RESULTS AND DISCUSSION}

Rauvolfia serpentina was selected on the basis of ethanobotanical history and their importance in Indian medicine system Ayurveda [39]. R. serpentina has been a widespread field for study due to its various phytochemical compounds that were used in herbal medicine as a potential source of valuable drugs for the treatment of numerous diseases [40]. Total 20 promising endophytic fungal isolates were recovered during rainy season from $R$. serpentina (Table 1). Out of 20 isolates, 9 isolates were recovered from stem, 7 from leaf and 4 from root. The maximum 54\% endophytic fungal strains were isolated from stem tissue, $26 \%$ from leaf tissue and 20\% from root tissue of R. serpentina (Fig. 1). Distribution of endophytic fungi in different tissues of $R$. serpentina had been reported in which Trichoderma, Nigrospora and Curvularia were dominant [41]. The identification of these isolated strains was based on colony morphology through light microscope. The fungal strains were identified and classified in eight genus as Fusarium sp. (Rs-R1, Rs-S8, Rs-L1, Rs-S7), Colletotrichum sp.(Rs-R5,Rs-S5), Xylaria sp. (Rs-L4, Rs-S3), Phomopsis sp. (Rs-R7B, Rs-L9), Alternaria sp. (Rs-L8, Rs-S6, Rs-S1, Rs-S11), Gleomastix sp. (Rs-L5, Rs-S2), Cladosporium sp. (Rs-S 4,Rs-R 2A), and Aspergillus sp. (Rs-L3A, Rs-L 6) (Table 2). The term "isolates" were used in this study for fungi isolated from different part of $R$. serpentina, showing similar genera characters of colony having morphological dissimilarity in spores (Table 2). These isolates were fermented using potato dextrose broth medium and extracted for secondary metabolites using ethyl acetate. The extracts were studied for antibacterial activity. Similar or its derivative bioactive compound may be produce by endophytes as found in their hosts and they offer opportunities for drug discovery [42].

Table 1. Endophytic fungi isolates recovered from leaf, stem and root of $R$. serpentina.

\begin{tabular}{|c|c|c|c|c|}
\hline \multicolumn{5}{|c|}{ Number of Isolates } \\
\hline \multicolumn{5}{|c|}{ Sample tissue from $R$. serpentina } \\
\hline Fungal group & Leaf & Stem & Root & Total \\
\hline Fusarium sp. & 1 & 2 & 1 & 4 \\
\hline Phomopsis sp. & 1 & & 1 & 2 \\
\hline Colletotrichum sp. & - & 1 & 1 & 2 \\
\hline Cladosporium sp. & & 1 & 1 & 2 \\
\hline Aspergillus sp. & 2 & - & - & 2 \\
\hline Xylaria sp. & 1 & 1 & - & 2 \\
\hline Alterneria sp. & 1 & 3 & - & 4 \\
\hline Gleomastix sp. & 1 & 1 & & 2 \\
\hline Total & 7 & 9 & 4 & 20 \\
\hline
\end{tabular}

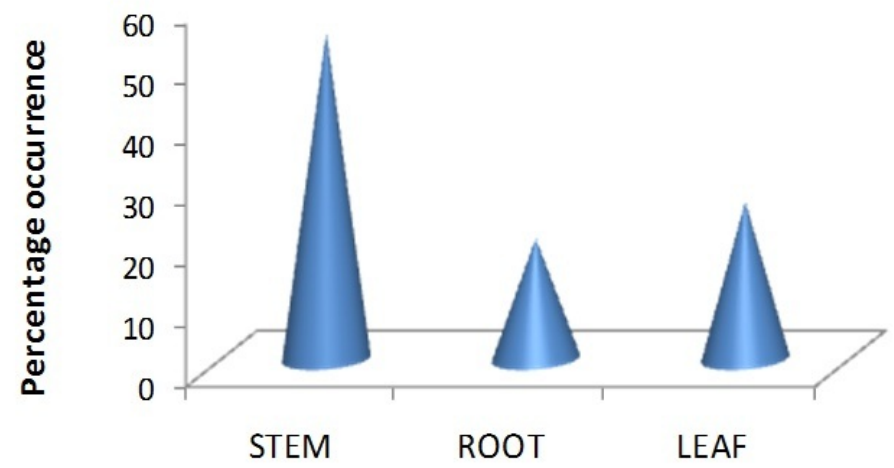

Fig. (1). Distribution of endophytic strains in R.serpentina. 
Table 2. Antibacterial activity of fungal extract against gram negative E.coli and Gram positive S. aureus.

\begin{tabular}{|c|c|c|c|c|}
\hline S.No. & Isolates & Fungal group & E. coli & S. aureus \\
\hline 1. & Rs-R 1 & \multirow[t]{4}{*}{ Fusarium sp. } & +++ & ++ \\
\hline 2. & Rs-S 8 & & - & - \\
\hline 3. & Rs-L1 & & - & - \\
\hline 4. & Rs-S7 & & + & + \\
\hline 5. & Rs-R 5 & \multirow[t]{2}{*}{ Colletotrichum sp. } & +++ & +++ \\
\hline 6. & Rs-S 5 & & - & - \\
\hline 7. & Rs-L 4 & \multirow[t]{2}{*}{ Xylaria $s p}$. & - & - \\
\hline 8. & Rs-S3 & & - & - \\
\hline 9. & Rs-R 7B & \multirow[t]{2}{*}{ Phomopsis sp. } & - & - \\
\hline 10. & Rs-L 9 & & - & - \\
\hline 11. & Rs-S 4 & \multirow[t]{2}{*}{ Clasporium sp. } & ++ & ++ \\
\hline 12. & Rs-R 2A & & - & - \\
\hline 13. & Rs-L 8 & \multirow[t]{4}{*}{ Alternaria sp. } & - & - \\
\hline 14. & Rs-S 6 & & - & - \\
\hline 15. & Rs-S 1 & & - & - \\
\hline 16. & Rs-S 11 & & - & - \\
\hline 17. & Rs-L 5 & \multirow[t]{2}{*}{ Gleomastix sp. } & - & - \\
\hline 18. & Rs-S2 & & - & - \\
\hline 19. & Rs-L 3A & \multirow[t]{2}{*}{ Aspergillus sp. } & - & - \\
\hline 20. & Rs-L 6 & & - & - \\
\hline
\end{tabular}

R, root; S, stem; L, leaf; +, Zone of inhibition ranged between 7 to $12 \mathrm{~mm}$; ++, Zone of inhibition ranged between 13 to $19 \mathrm{~mm}$; +++, zone of inhibition greater than $20 \mathrm{~mm}$; -, No inhibition zone.

Antibacterial activity of methanolic fungal extract of all 20 isolates was evaluated against pathogenic bacterial strains. Out of 20 isolates only 4 isolates (Rs-R1, Rs-S4, Rs-R5 and Rs-S7) possesses antibacterial activity in which two fungal isolates (Rs-R1 and Rs-R5) showed more potency while other two isolates (Rs-S4 and Rs-S7) showed less activity against the bacterial strains (Table 2). Antibacterial activity was reported in various genus of endophytic fungus isolated from R. serpentina against E.coli and S.aureus [43]. Endophytic fungi Colletotrichum gloeosporioides, Penicillium sp. and Aspergillus awamori, isolated from $R$. serpentina had promising antibacterial, antifungal, hypocholesterolemic and antioxidant activity [44]. Primary Screening for secondary metabolites of these four antibacterial fungal strains revealed the presence of alkaloids, flavonoids, polyphenols, saponins and steroids but absence of tannins (Table 3). The crude extract obtained from the bioactive endophytes was subjected to the different column of organic solvents with increasing order of their polarities (as follows n- hexane, benzene, chloroform, ethyl acetate and methanol). Alkaloids were present in the chloroform and ethyl acetate fraction. Steroids were present in hexane fraction and ethyl acetate fraction. Polyphenols and flavonoids both were present in ethyl acetate and methanol. Saponins were present in ethyl acetate however tannins were absent in all the extracts. Secondary metabolites obtained from fungal endophytes have a broad spectrum of biological activities such as antimicrobial, antiviral, antioxidant and anticancer [23, 43, 24]. Phytochemicals like alkaloids, polyphenols, flavonoids and steroid were observed while saponins and tannins were absent in crude extract of Rs-R5. Alkaloids, polyphenols, flavonoids, steroids and saponins were present in Rs-R1 however tannins were absent. Rs-S4 crude extract marked the presence of alkaloids, polyphenols, flavonoids and steroid while saponins and tannins were absent. Alkaloids, polyphenols, flavonoids were present in the crude extract of Fusarium sp. (Rs-S7) but steroids and tannins were absent (Table 4). Fungal extracted in Ethyl acetate and methanol was more effective against target bacterial strains than extract of other organic solvents. Ethyl acetate extract of Colletotrichum sp. (Rs-R5) had shown $14 \mathrm{~mm}$ inhibition zone against $S$. aureus (ATCC 25323) and $16 \mathrm{~mm}$ inhibition zone against $E$. coli (ATCC 25922) while other fungal extracts had less inhibition zone such as Fusarium sp. (Rs-R1) had $13 \mathrm{~mm}$ and $12 \mathrm{~mm}$ and Cladosporium sp (Rs-S4) $9 \mathrm{~mm}$ and $11 \mathrm{~mm}$ had inhibition zone against E. coli (ATCC 25922) and S. aureus (ATCC 25323) respectively. While Fusarium sp. (Rs-S7)shown 7 mm inhibition zone against E. coli (ATCC 25922) and $6 \mathrm{~mm}$ inhibition zone against $S$. aureus (ATCC 25323) (Fig. 2). The MIC value of extract of Colletotrichum sp. (Rs-R5) was $25.0 \mu \mathrm{g} / \mathrm{ml}$ for E. coli (ATCC 25922) and $35.5 \mu \mathrm{g} / \mathrm{ml}$ for S. aureus (ATCC 25323). The MIC value of extract of Cladosporium sp (Rs-S4) was $38.5 \mu \mathrm{g} / \mathrm{ml}$ and $50.5 \mu \mathrm{g} / \mathrm{ml}$ for E. coli and S. aureus respectively. While MIC value of extract of Fusarium sp. (Rs-R1)was $40.5 \mu \mathrm{g} / \mathrm{ml}$ and $60.0 \mu \mathrm{g} / \mathrm{ml}$ for E. coli 
and S. aureus respectively. The MIC value of extract of Fusarium sp. (Rs-S7)was $65.5 \mu \mathrm{g} / \mathrm{ml}$ for E. coli and 70.0 $\mu \mathrm{g}$ $/ \mathrm{ml}$ for $S$. aureus (Table 5). Fresh bacterial broth cultures were prepared before screening procedure. The positive control was streptomycin $(0.1 \mu \mathrm{g} / \mathrm{ml}$ ) against E.coli (ATCC 25922) and S. aureus (ATCC 25323) [7]. Ethyl acetate extract of endophytic fungi Fusarium sp. and Aspergillus sp. isolated from Withania somnifera were reported for significant inhibition against E.coli and $S$. aureus [45].
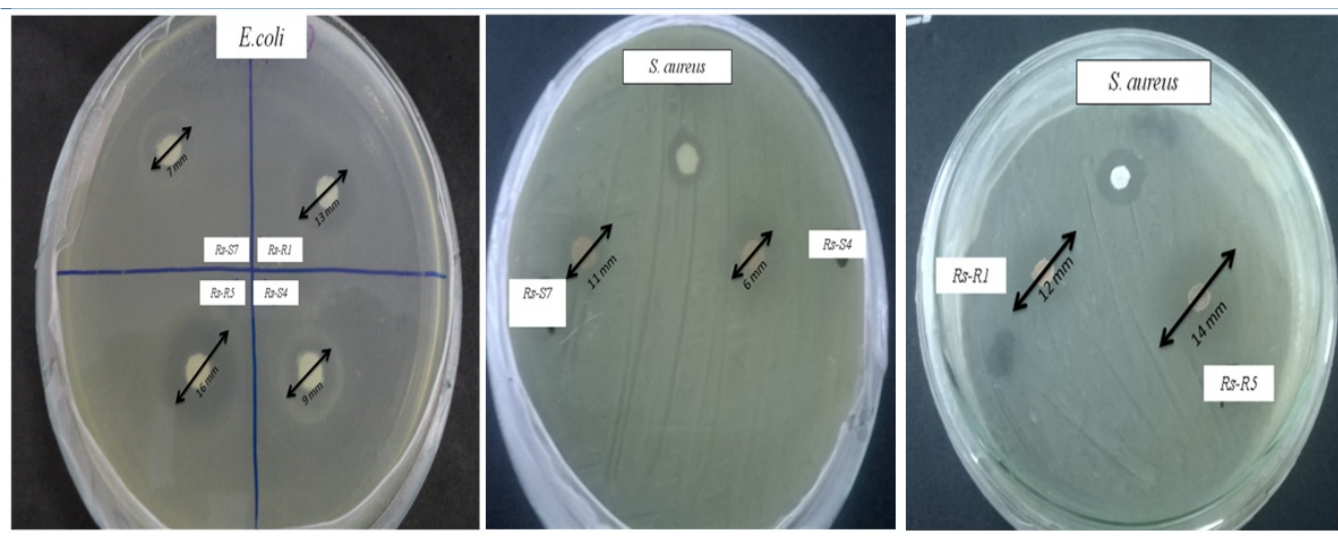

Fig. (2). Antibacterial bioassay by disc diffusion method. Inhibition zone of extracts. a Rs-R5,Rs-R1, Rs-S4, Rs-S7 on E. coli, b RsS4and Rs-S7 on S.aureus, c Rs-R1 and Rs-R5 on S.aureus cultured plates.

Table 3. Primary Screening for secondary metabolites of endophytic fungi of $R$. serpentina.

\begin{tabular}{|c|c|c|c|c|c|c|}
\hline Fungal Species & Alkaloids & Flavonoids & Polyphenols & Steroids & Saponins & Tannins \\
\hline $\begin{array}{c}\text { RS-R5 } \\
\text { Colletotrichum sp. }\end{array}$ & +++ & ++ & ++ & + & - & - \\
\hline $\begin{array}{c}\text { RS-R1 } \\
\text { Fusarium sp. }\end{array}$ & ++ & +++ & ++ & - & + & - \\
\hline $\begin{array}{c}\text { RS-S4 } \\
\text { Cladosporium sp. }\end{array}$ & ++ & + & + & + & - & - \\
\hline $\begin{array}{c}\text { RS-S7 } \\
\text { Fusarium sp. }\end{array}$ & ++ & + & + & - & + & - \\
\hline
\end{tabular}

Phomopsichalasin, a secondary metabolite isolated from an endophytic Phomopsis sp., represents the first cytochalasin-type compound which exhibits antibacterial activity in disc diffusion assays against B. subtilis (12-mm zone of inhibition), S. aureus (8-mm zone of inhibition) and Salmonella entericaserovar Gallinarum (11-mm zone of inhibition). It also displays a moderate activity against the yeast Candida tropicalis (8-mm zone of inhibition) [46].

Table 4. Phytochemical screening of crude extract of active strains in different solvents.

\begin{tabular}{|c|c|c|c|c|c|}
\hline Fungal Strains & n-Hexane & Benzene & Chloroform & Ethyl acetate & Methanol \\
\hline Rs-S4 & $\mathrm{St}$ & - & $\mathrm{Al}$ & $\mathrm{Al}, \mathrm{Fl}, \mathrm{Pl}, \mathrm{St}, \mathrm{Sp}$ & $\mathrm{Al}, \mathrm{Fl}, \mathrm{Pl}, \mathrm{St}$ \\
\hline Rs-S7 & - & - & $\mathrm{Al}$ & $\mathrm{Al}, \mathrm{Fl}, \mathrm{Pl}, \mathrm{Sp}$ & $\mathrm{Fl}, \mathrm{Pl}$ \\
\hline Rs-R1 & $\mathrm{St}$ & - & $\mathrm{Al}$ & $\mathrm{Al}, \mathrm{Fl}, \mathrm{Pl}, \mathrm{St}, \mathrm{Sp}$ & $\mathrm{Pl}, \mathrm{Pl}$ \\
\hline Rs-R5 & $\mathrm{St}$ & - & $\mathrm{Al}$ & $\mathrm{Al}, \mathrm{Fl}, \mathrm{Pl}, \mathrm{St}$ & $\mathrm{Fl}, \mathrm{Pl}$ \\
\hline Al: Alkaloids, Fl: Flavonoids, Pl: Polyphenols, St: Steroids and Sp: Saponins \\
\hline
\end{tabular}

The morphology of four active strains was further identified through Light microscope and Scanning Electron Microscope (Fig. 3). According to morphology of spores and hyphae, two antibacterial isolates were recognized as Fusarium sp. (Rs-R1) and (Rs-S7). Spores were septed, fusiform (half moon shaped) and pointed at tip (Figs. 3b, 3d). Conidiophores of Cladosporium $s p$. (Rs-S 4) were geniculate bearing terminal and intercalary swellings and produce two to four celled conidia (Fig. 3c). The cultures of Colletotrichum sp.was distinct with fast growing sparse aerial mycelium, white with copious cinnamon conidial masses, conidia usually elliptical and setae absent (Fig. 3a). 

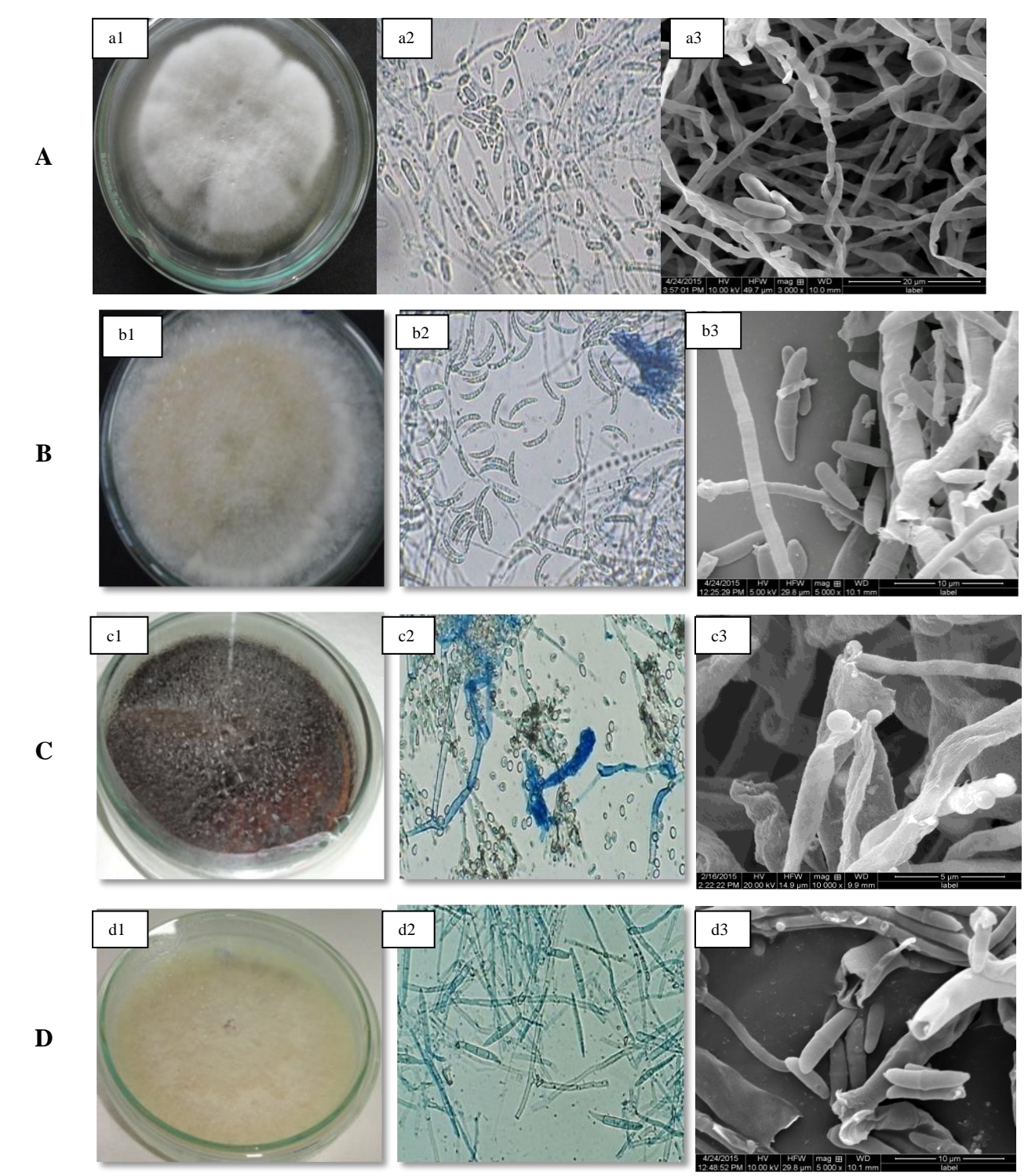

A. shows Colletotrichum sp.; B. and D. shows Fusarium sp.; C. shows Cladosporium sp.

$\mathrm{a} 1, \mathrm{~b} 1, \mathrm{c} 1, \mathrm{~d} 1$ shows the PDA plate colony, a2,b2,c2,d2 shows the light microscopy images and a3,b3,c3,d3 shows SEM images.

Fig. (3). Morphology of fungal isolates having antibacterial activity.

The results revealed that four out of twenty endophytic strains were significantly effective against target bacteria. Extract of Fusarium sp. (Rs-R1, Rs-S7), Colletotrichum sp. (Rs-R5) and Cladosporium sp. (Rs-S4)showed antibacterial activity (Table 2). These four endophytic fungi were selected for further study. However, the extract of one isolate Colletotrichum sp. showed relatively higher antibacterial activity in comparison to other test fungal strains against both the test bacteria. Extract of Cladosporium sp. (Rs-S4) hadshown higher antibacterial activity against Grampositivebacteria S. aureus (ATCC 25323) in comparison to Gram-negativebacteria E. coli (ATCC 25922).RS-R5 was most effective against Gram positive and Gram negative bacteria, however, RS-R1 \& RS-S4 were moderately effective and RS-S7 was less effective. These findings support the observations of other scientists regarding antibacterial potency of endophytic fungal strains. Our results suggest that the bioactive molecules from the extract of isolated endophytes may be a source of broad spectrum antibacterial molecules. The extract of endophytes of $R$. serpentina may be potent sources for antibacterial activity. This study shows that endophytic fungi are potent source of secondary metabolites. The combined knowledge of microbial biodiversity, bioprospecting rational and random mutagenesis knowledge will provide the necessary base and tools to identify and culture endophytes on an economically viable scale that produce novel potent antibiotics, organic acids, pharmaceutically active lead metabolites and other bioactive secondary metabolites [21, 47]. With utilization of modern techniques of fermentation, it is possible to harvest the antimicrobial 
metabolites in large quantities to prepare cost-effective antibiotics. So endophytes may be used as biological factory to produce bioactive compounds which are natural, inexpensive, safe, fast, reproducible, unlimited and weather/season independent.

Table 5. Inhibition zone \& MIC of the ethyl acetate extract against E.coli and S. aureus.

\begin{tabular}{|c|c|c|c|c|c|}
\hline \multirow{2}{*}{ S.No. } & \multirow{2}{*}{ Fungal Isolates } & \multicolumn{2}{|c|}{ Inhibition zone $(\mathbf{m m})$} & \multicolumn{2}{|c|}{ MIC values $(\boldsymbol{\mu g} / \mathbf{m l})$} \\
\cline { 3 - 6 } & & $\boldsymbol{E}$ coli & S. aureus & E. coli & S. aureus \\
\hline 1. & Rs-R5 & 16 & 14 & 25.0 & 36.5 \\
\hline 2. & Rs-R1 & 13 & 12 & 42.5 & 60.0 \\
\hline 3. & Rs-S4 & 9 & 11 & 38.5 & 51.5 \\
\hline 4. & Rs-S7 & 7 & 6 & 65.5 & 71.1 \\
\hline
\end{tabular}

\section{CONCLUSION}

There are eight endophytic fungal genus isolated from $R$. serpentina as follows Fusarium sp., Alternaria sp., Phomopsis sp., Xylaria sp., Gleomastix sp., Aspergillus sp., Cladosporium sp. and Colletotrichum sp. The study had shown 4 isolates out of 20 fungal isolates i.e. Fusarium sp. (Rs-R1, Rs-S7), Cladosporium sp. (Rs-R5) and Colletotrichum $s p$. (Rs-R5) had shown antibacterial activity. Inhibition zone and MIC was observed using the extract of ethyl acetate. The maximum inhibition zone $(16 \mathrm{~mm})$ and minimum MIC $(25 \mu \mathrm{g} / \mathrm{ml})$ was observed against $E$. coli. The ethyl acetate extract was found rich in secondary metabolites like alkaloids, polyphenols, flavonoids, steroids and saponins.

\section{LIST OF ABBREVIATIONS}

Rs-S: Isolate of stem of Rauvolfia serpentina.

Rs-L: Isolate of leaf of Rauvolfia serpentina.

Rs-R: Isolate of root of Rauvolfia serpentina.

MIC: Minimum Inhibitory Concentration.

ATCC: American Type Culture Collection.

\section{CONFLICT OF INTEREST}

The authors confirm that this article content has no conflict of interest.

\section{ACKNOWLEDGEMENTS}

Authors wish to thank the Professor-In charge, Centre of Experimental Medicine and Surgery, Institute of Medical Sciences, Banaras Hindu University for providing infrastructure facilities and continuous support. Authors are also thankful to the Science and Engineering Research Board, DST, Govt. of India for providing financial support to the research work (File. No. SERB/SR/SO/PS/22/2012).

\section{REFERENCES}

[1] Chopra, R.N.; Nayar, S.L.; Chopra, I.C. Glossary of Indian Medicinal Plants. NISCIR; CSIR: Delhi, 2002.

[2] Govternment of India. Ayurvedic Pharmacopoeia of India; Part-2, Vol-1, 2007.

[3] Arts, I.C.; Hollman, P.C. Polyphenols and disease risk in epidemiologic studies. Am. J. Clin. Nutr., 2005, 81(1)(Suppl.), 317S-325S. [PMID: 15640497]

[4] Scalbert, A.; Manach, C.; Morand, C.; Rémésy, C.; Jiménez, L. Dietary polyphenols and the prevention of diseases. Crit. Rev. Food Sci. Nutr., 2005, 45(4), 287-306.

[http://dx.doi.org/10.1080/1040869059096] [PMID: 16047496]

[5] Harisaranraj, R.; Suresh, K.; Babu, S.S. Phytochemical based strategies for pathogen control and antioxidant capacities of Rauvolfia serpentina Extracts. Recent Res. Sci. Technol., 2009, 1, 67-73.

[6] Ezeigbo, I.I.; Ezeja, M.I.; Madubuike, K.G.; Ifenkwe, D.C.; Ukweni, I.A.; Udeh, N.E.; Akomas, S.C. Antidiarrhoeal activity of leaf methanolic extract of Rauwolfia serpentina. Asian Pac. J. Trop. Biomed., 2012, 2(6), 430-432. [http://dx.doi.org/10.1016/S2221-1691(12)60070-7] [PMID: 23569944]

[7] Rathi, P.; Kumari, R.; Chatrasal, S. Therapeutic characteristics of Rauvolfia serpentina. Int. J. Pharm. Pharm. Sci., 2013, 2(2), 1038-1042. 
[8] Yu, J.; Ma, Y.; Drisko, J.; Chen, Q. Antitumor activities of Rauvolfia vomitoria extract and potentiation of carboplatin effects against ovarian cancer. Curr. Ther. Res. Clin. Exp., 2013, 75, 8-14. [http://dx.doi.org/10.1016/j.curtheres.2013.04.001] [PMID: 24465036]

[9] Harisaranraj, R.; Suresh, K.; Saravanababu, S. Evaluation of the chemical composition Rauwolfia serpentina and Ephedra vulgeris. Adv. Biol. Res. (Faisalabad), 2009, 3(5-6), 174-178.

[10] Vakil, R.J. Rauwolfia serpentina in the treatment of high blood pressure. American Heart Association,Inc., 1955. Available at: circ.ahajournals.org/content/12/2/220.abstract.

[11] Stary, F. The Natural Guide to Medicinal Herbs sand Plants. Tiger Books International: London, 1998, pp. 12-16.

[12] Okwu, D.E.; Okwu, M.E. Chemical composition of Spondias mombin linn plant parts. J. Sustain. Agric. Environ., 2004, 6(2), 140-147.

[13] Neuss, N.; Phillipson, J.D.; Zenk, M.H. Indole and Biogenetically Related Alkaloids; Academic Press: New York, 1980.

[14] Stierle, A.; Strobel, G.; Stierle, D. Taxol and taxane production by Taxomyces andreanae, an endophytic fungus of Pacific yew. Science, 1993, 260(5105), 214-216. [http://dx.doi.org/10.1126/science.8097061] [PMID: 8097061]

[15] Pu, X.; Qu, X.; Chen, F. Camptothecin-producing endophytic fungus trichoderma atroviride ly357: isolation, identification, and fermentation conditions optimization for camptothecin production. Appl. Microbiol. Biotechnol, 2013, 97(21), 9365-75.

[16] Eyberger, AL.; Dondapati, R.; Porter, J. R. Endophyte fungal isolates from podophyllum peltatum produce podophyllotoxin. J. Nat. Prod, 2006, 69(8), 1121-4.

[17] Kusari, S.; Lamshöft, M.; Zühlke, S.; Spiteller, M. An endophytic fungus from Hypericum perforatum that produces hypericin. J. Nat. Prod., 2008, 71(2), 159-162. [http://dx.doi.org/10.1021/np070669k] [PMID: 18220354]

[18] Verma, V.C.; Lobkovsky, E.; Gange, A.C.; Singh, S.K.; Prakash, S. Piperine production by endophytic fungus Periconia sp. isolated from Piper longum L. J. Antibiot., 2011, 64(6), 427-431. [http://dx.doi.org/10.1038/ja.2011.27] [PMID: 21505472]

[19] Stone, J.K.; Bscon, C.W.; White, J.F. An overview of endophytic microbes: endophytism defined. In: MicrobialEndophytes; Marcel Dekker: New York, 2000; pp. 3-29.

[20] Schulz, B.; Boyle, C. What are endophytes? In: Microbial Roots Endophytes; Springer-Verlag: Berlin, $2006 ;$ pp. 1-13. [http://dx.doi.org/10.1007/3-540-33526-9_1]

[21] Strobel, G.; Daisy, B. Bioprospecting for microbial endophytes and their natural products. Microbiol. Mol. Biol. Rev., 2003, 67(4), 491-502. [http://dx.doi.org/10.1128/MMBR.67.4.491-502.2003] [PMID: 14665674]

[22] Paul, A.B.; Richard, A.S. Endophytes: An emerging tool for biological control. Biol. Control, 2008, 46, 1-3 [http://dx.doi.org/10.1016/j.biocontrol.2008.03.009]

[23] Strobel, G.A. Rainforest endophytes and bioactive products. Crit. Rev. Biotechnol., 2002, 22(4), $315-333$. [http://dx.doi.org/10.1080/07388550290789531] [PMID: 12487423]

[24] Wiyakrutta, S.; Sriubolmas, N.; Panphut, W. Endophytic fungi with anti-microbial, anti-cancer and anti-malarial activities isolated from Thai medicinal plants. World J. Microbiol. Biotechnol., 2004, 20, 265-272. [http://dx.doi.org/10.1023/B:WIBI.0000023832.27679.a8]

[25] Hallmann, J.; Berg, G.; Schulz, B. Isolation Procedures for Endophytic Microorganisms; Springer: New York, 2007.

[26] Gilman, J.C. A Manual of Soil Fungi; The Lowa State Press: Ames lowa, USA, 1959.

[27] Ellis, M.B. Dematiaceous Hypomycetes; Common Wealth Mycological Institute: Kew, Surrey, England, 1971.

[28] Raper, K.B.; Thom, C.; Fennel, D.I. Manual of Penicillia; The Williams \& Wilkins Co.: Baltimore, USA, 1949.

[29] Barnett, H.L. Illustrated genera of Imperfect Fungi., Minneapolis, 1962.

[30] Nitya, K.; Murthy, K.C.; Pushpalatha, C.G.J. Antioxidant activity and phytochemical analysis of endophytic fungi isolated from Lobelia nicotianifolia. J. Chem. Pharm. Res., 2011, 3(5), 218-225.

[31] de Barros, B.S.; da Silva, J.P.; de Souza Ferro, J.N.; Agra, I.K.; de Almeida Brito, F.; Albuquerque, E.D.; Caetano, L.C.; Barreto, E. Methanol extract from mycelium of endophytic fungus Rhizoctonia sp. induces antinociceptive and anti-inflammatory activities in mice. J. Nat. Med., 2011, 65(3-4), 526-531. [http://dx.doi.org/10.1007/s11418-011-0534-x] [PMID: 21625947]

[32] Devi, P.; D’Souza, L.; Kamat, T. Batch culture fermentation of Penicillium chrysogenum and a report on the isolation, purification, identification and antibiotic activity of citrinin. Indian J. Mar. Sci., 2009, 38, 38-44.

[33] Clinical and Laboratory Standards Institute. Performance Standards for Antimicrobial Disk Susceptibility Tests; Seventeenth Informational Supplement M100-S17; USA: Pennsylvania, 2007, p. 19087.

[34] Handunnetti, S.M.; Kumara, R.R.; Deraniyagala, S.A. Anti- inflammatory activity of Ixora coccinea methanolic leaf extract. Pharmacogen. Res, 2009, 1(2), 80-90. 
[35] Makris, D.P.; Boskou, G.; Andrikopoulos, N.K. Recovery of antioxidant phenolics from white vinification solid by-products employing water/ethanol mixtures. Bioresour. Technol., 2007, 98(15), 2963-2967. [http://dx.doi.org/10.1016/j.biortech.2006.10.003] [PMID: 17110101]

[36] Lapornik, B.; Prošek, M. Golc Wondra. A. Comparison of extracts prepared from plant by-products using different solvent and extraction time. J. Food Eng., 2005, 71, 214-222. [http://dx.doi.org/10.1016/j.jfoodeng.2004.10.036]

[37] Harborne, J.B. Phytochemical Methods: A Guide to Modern Technique of Plant Analysis; Champman and Hall: London, 1998.

[38] Sofowora, A. Screening Plants for Bioactive Agents. In: Medicinal Plants and Traditional Medicinal in Africa, $2^{\text {nd }}$ ed; Spectrum Books Ltd, Sunshine House: Ibadan, Nigeria, 1982; pp. 134-156.

[39] Pant, K.K.; Joshi, S.D. Rapid multiplication of Rauvolfia serpentina Benth. Ex. Kurz through tissue culture. Sci. World J., 2008, 6, 58-62.

[40] Kumari, R.; Rathi, B.; Rani, A. Bhatnagar, S. Rauvolfia serpentina L. Benth. ex Kurz. Phytochem. Pharmacological and Therapeutic Aspects. Int. J. Pharm. Sci. Rev. Res., 2013, 23(2), 348-355.

[41] Doley, P.; Jha, D.K. Endophytic fungal assemblages from ethnomedicinal plant Rauwolfia serpentina (L). Benth. J. Plant Pathol. Microbiol, 2010, 40(1), 44-48.

[42] Strobel, G.; Daisy, B.; Castillo, U.; Harper, J. Natural products from endophytic microorganisms. J. Nat. Prod., 2004, 67(2), 257-268. [http://dx.doi.org/10.1021/np030397v] [PMID: 14987067]

[43] Qadri, M.; Johri, S.; Shah, B.A.; Khajuria, A.; Sidiq, T.; Lattoo, S.K.; Abdin, M.Z.; Riyaz-Ul-Hassan, S. Identification and bioactive potential of endophytic fungi isolated from selected plants of the Western Himalayas. Springerplus, 2013, $2(1), 8$. [http://dx.doi.org/10.1186/2193-1801-2-8] [PMID: 23420270]

[44] Nath, A.; Chattopadhyay, A.; Joshi, S.R. Biological activity of endophytic fungi of Rauwolfia serpentina Benth: An ethnomedicinal plant used in folk medicines in Northeast India. Proc. Natl. Acad. Sci., India, Sect. B Biol. Sci., 2015, 85(1), 233-240. [http://dx.doi.org/10.1007/s40011-013-0184-8]

[45] Salini, T.S.; Dibu, D.; Shabanamol, S. Antimicrobial and immunomodulatory potential of endophytic fungus Fusarium solani isolated from Withania somnifera. World J. Pharm. Res., 2014, 3(10), 879-890.

[46] Horn, W.S.; Simmonds, M.S.; Schwartz, R.E. Phomopsichalasin, a novel antimicrobial agent from an endophytic Phomopsis sp. Tetrahedron, 1995, 14, 3969-3978. [http://dx.doi.org/10.1016/0040-4020(95)00139-Y]

[47] Desale, M.G.; Bodhankar, M.G. Antimicrobial activity of endophytic fungi isolated from Vitex negundo Linn. Int. J. Curr. Microbiol. App. Sci., 2013, 2(12), 389-395.

\section{C) Singh et al.; Licensee Bentham Open.}

This is an open access article licensed under the terms of the Creative Commons Attribution-Non-Commercial 4.0 International Public License (CC BY-NC 4.0) (https://creativecommons.org/licenses/by-nc/4.0/legalcode), which permits unrestricted, non-commercial use, distribution and reproduction in any medium, provided the work is properly cited. 